\title{
0 poema//processo de Wlademir Dias-Pino: entre escritura e visualidade
}

\section{The Wlademir Dias-Pino's Poem//Process: Between the Writing and Visuality}

\section{El poema//proceso de Wlademir Dias-Pino: entre escritura y visualidad}

\author{
Thiago Grisolia Fernandes *
}

http://dx.doi.org/10.22409/poiesis.2033.355-374

\begin{abstract}
RESUMO: O presente artigo apresenta o movimento do poema//processo, criado pelo poeta mato-grossense Wlademir Dias-Pino em 1967, que envolveu uma série de poetas e artistas e marcou uma passagem importante na história das vanguardas da literatura e da arte brasileiras. A partir dos principais conceitos do movimento, trataremos das imbricações entre poesia e artes visuais utilizando três abordagens inter-relacionadas na poesia de Dias-Pino: a separação entre as ideias de estrutura e de processo; a separação entre as ideias de língua e de linguagem; e a recusa radical à escrita alfabética. Também serão marcados os aspectos que aproximam e que separam o poema//processo da chamada poesia visual e da Poesia Concreta de Haroldo e Augusto de Campos e de Décio Pignatari.
\end{abstract}

PALAVRAS-CHAVE: Wlademir Dias-Pino; poema//processo; poesia visual

\footnotetext{
" Thiago Grisolia Fernandes é doutorando em Ciência da Literatura pela Universidade Federal do Rio de Janeiro (UFRJ), mestre em Estudos Contemporâneos das Artes (2015) e bacharel em Produção Cultural (2012) pela Universidade Federal Fluminense (UFF). E-mail: goathigrisolia@yahoo.com. Orcid: https://orcid.org/0000-00020856-8528
} 
ABSTRACT: This paper presents the movement called poem//process, created by the poet from Mato Grosso Wlademir Dias-Pino in 1967, which involved a series of poets and artists and marked an important passage in the history of the avant-garde of Brazilian literature and art. From the main concepts of the movement, we will talk about the imbrications between poetry and visual arts by using three interrelated dimensions in Dias-Pino's poetry: the separation between the concepts of structure and of process; the separation between the concepts of idiom and language; and a radical refusal to alphabetic writing. Also will be marked the aspects that approach and separate the poem//process of the socalled visual poetry and Concrete Poetry of Haroldo and Augusto de Campos and Décio Pignatari.

KEYWORDS: Wlademir Dias-Pino; poem//process; visual poetry

RESUMEN: El presente artículo presenta el movimiento del poema//proceso, creado por el poeta mato-grossense Wlademir Dias-Pino en 1967, que envolvió una serie de poetas y artistas y marcó un pasaje importante en la historia de las vanguardias de la literatura y del arte brasileñas. A partir de los principales conceptos del movimiento, trataremos de las imbricaciones entre poesía y artes visuales utilizando tres enfoques interrelacionados en la poesía de Días-Pino: la separación entre las ideas de estructura y de proceso; la separación entre las ideas de lengua y de lenguaje; y el rechazo radical a la escritura alfabética. También se marcarán los aspectos que aproximan y que separan el poema//proceso de la llamada poesía visual y de la Poesía Concreta de Haroldo y Augusto de Campos y de Décio Pignatari.

PALABRAS CLAVE: Wlademir Días-Pino; poema//proceso; poesía visual

Como citar: FERNANDES, Thiago Grisolia. O poema//processo de Wlademir DiasPino: entre escritura e visualidade. Poiésis, Niterói, v. 20, n. 33, p. 355-374, jan./jun. 2019.

doi: http://dx.doi.org/10.22409/poiesis.2033.355-374

Poiésis, Niterói, v. 20, n. 33, jan./jun. 2019. 


\section{0 poema//processo de Wlademir Dias-Pino: entre escritura e visualidade}

O poeta Wlademir Dias-Pino (1927-2018), ao ser perguntado ${ }^{1}$ sobre o motivo pelo qual o poema//processo ${ }^{2}$, movimento de vanguarda criado por ele e por vários outros poetas na década de 1960, não obteve o espaço que, supunha-se, Ihe caberia na história da literatura brasileira, sugere que se abra a primeira página do catálogo da exposição retrospectiva de sua obra, no Oi Futuro/Rio de Janeiro, em 2010. Ali, em letras maiúsculas, lê-se a seguinte citação do próprio Wlademir: "O CÓDIGO ALFABÉTICO É, POR CERTO, O INSTRUMENTO MAIS CRUEL QUE O HOMEM JÁ INVENTOU". (DIAS-PINO, 2010, s/p) E, então, o poeta se pergunta como a crítica poderia levar em consideração um movimento de poesia que se baseia em uma afirmação como essa: a poesia visual exigiria uma crítica igualmente visual, e o poema de processo exigiria uma crítica de processo, que simplesmente não existe. 
O que ocorre é que, para ele, a escrita alfabética teria aprisionado a poesia, limitando sua possibilidade de expandir-se, de atingir um maior leque de sua verdadeira potência; ela proporciona o desenvolvimento das línguas a que se permite a poesia, mas não de suas linguagens. Essa distinção entre língua e linguagem é fundamental para o poema//processo, na medida em que evidencia a diferença, para o poeta, entre a Poesia e o Poema. Diz ele:

\section{Os poetas do movimento do Poema-Processo (livres do sofisticado do heroísmo) têm a consciência das di- ficuldades de ser vanguarda e mais do que isso, sabem que ao dissociar a Poesia (estrutura) do Poema (processo), separaram, definitivamente, o que é língua de linguagem dentro da literatura. (DIAS-PINO, $1971, s / p)$}

Neste sentido, Wlademir Dias-Pino pontua, já de saída, que suas operações poéticas se baseiam em uma renúncia primordial: a renúncia à palavra pensada em seu sentido positivo; e que esta renúncia não implica em uma falta, em um déficit ou em uma pobreza, mas em uma concepção processual da linguagem, que será trabalhada neste artigo.

Embora seja possível flagrar essa intensidade não-vocabular em trabalhos como o grande poema A AVE, escrito entre 1948 e 1956, anterior, portanto, à criação do movimento do poema//processo, que teve como marco inicial e data de publicação de seu primeiro manifesto o ano de 1967, este texto abordará algumas questões a respeito desse movimento, já que ele institui, vanguardisticamente, vários dos pressupostos poéticos que já estavam presentes desde $A$ AVE, e desde o início da trajetória de Wlademir ${ }^{3}$. Um desses pressupostos, o principal deles, é justamente essa tríade - que deve ser pensada, em nível de estudo da vasta obra deste poeta, de maneira indissociável: a separação entre as ideias de estrutura e de processo; a separação entre as ideias de língua e de linguagem; e a recusa à escrita alfabética.

Seu movimento nasce, de algum modo, no esteio de sua ruptura com o movimento da Poesia Concreta; embora tenha sido um de seus fundadores, Wlademir aponta de modo contundente alguns problemas relativos ao que ele chama de grupo concretista, e não de

Poiésis, Niterói, v. 20, n. 33, jan./jun. 2019. 
movimento: o principal deles seria o de que os manifestos, notadamente os publicados em 1956 (CAMPOS, A. de; PIGNATARI, D.; CAMPOS, H. de, 2006), são assinados pelos integrantes do Noigandres, Haroldo de Campos, Augusto de Campos e Décio Pignatari, não cumprindo, portanto, a função de um manifesto, que seria a de revelar as intenções de um movimento de vanguarda. Sendo o Noigandres um grupo de três pessoas, não seria razoável considerá-los como um movimento; o que melhor poderia ter se aproximado de um manifesto da poesia concreta se encontraria discretamente publicado em uma página da revista O Cruzeiro, de 2 de março de $1957^{4}$. A matéria de que se trata, segundo Wlademir, teria sido fruto de uma conversa com os seis poetas que fundaram a poesia concreta no Brasil: Haroldo, Augusto, Décio, mas também Ferreira Gullar, Ronaldo Azeredo e o próprio Wlademir. Ferreira Gullar, contudo, em Experiência neoconcreta: momento-limite da arte (2007), referindo-se à fundação do concretismo no Brasil, inclui no grupo fundador do movimento os nomes de Oliveira Bastos e Reynaldo Jardim, e faz afirmações como a de que "[0] poema visual foi uma criação dos três poetas paulistas e constituiu uma inovação de indiscutível originalidade que, se dependesse de mim, não teria existido" (GULLAR, 2007, p. 22), sem sequer citar o nome de Wlademir que, desde 1948, já vinha trabalhando em seu poema A AVE e desenvolvendo forte pesquisa poética de cunho visual.

É interessante notar que, mesmo nesta reportagem, onde se considera a participação dos seis poetas na poesia concreta, já se pode observar uma distinção de Wlademir em relação aos demais. O texto, intitulado justamente "A desintegração vocabular na poesia concreta", afirma o seguinte:

\section{As palavras, no poema, se desintegram, se dissociam, se esfacelam em sílabas e letras que se juntam ou não às palavras seguintes ou próximas. Segundo Décio Pignatari, esse é um caráter de transição na poesia concreta: "Nossa tendência é respeitar a integridade da palavra. Ela, e não a letra, é a base do poema". Mas em alguns concretos (Wladimir Dias Pino, por exemplo) isso chega ao ponto da eliminação do alfa- beto que é substituído por lugares geométricos, formas e cores. (DIAS-PINO, 2010, s/p).}

Ou seja, ao passo que Décio Pignatari, e com ele seus companheiros no Noigandres, estavam seguindo a tendência de "respeitar a integridade da palavra" como "base do poema", 
Wlademir, já àquela época, trabalhava na dinamitação da palavra e na "eliminação do alfabeto". E o que entra no lugar dessa escrita alfabética são justamente formas, cores, geometrias, aspectos usualmente relegados aos domínios das artes visuais.

Se, no entanto, Haroldo de Campos insistia em pensar, por exemplo, o trabalho da artista Mira Schendel, notadamente uma artista visual, no campo da poesia, dizendo sobre seu trabalho que "o quadro dela já é um poema, um poema-quadro, um quadro-poema" (CAMPOS, 1996, p. 234), por outro lado, aqui, no caso do poema//processo, vê-se um certo esforço da crítica de situá-lo no campo das artes visuais. Em forte texto publicado na Revista Ponto 2, em 1968, o poeta Moacy Cirne coloca em jogo essa visada, afirmando o seguinte:

Muitos têm insistido em situar o poema/processo na área das artes plásticas. Certamente - e a última fase da poesia concreta já o mostrara - cada vez mais nos afastamos da literatura. Mais do que isso: 0s nossos críticos ainda não perceberam que a literatura por excelência do século XX é a estória-em-quadrinhos. [...] A poesia não poderia ficar presa ao jogo fácil das palavras, que puxam palavras - associações paranomásticas que não mais funcionam -, nem a falsa engenharia estrutural / que termina na mais pura esterilidade. A crise da poesia é simplesmente a crise da palavra (no poema). (CIRNE, 1968, s/p)

Ora, por certo o poema//processo, mais do que qualquer dos poemas de todas as fases da poesia concreta brasileira, afasta-se da literatura, para usar a expressão de Moacy, mas apenas na medida em que não considera a palavra como base do poema, como Pignatari - e, talvez por isso, Wlademir tenha indicado sua citação a respeito da escrita alfabética como resposta para o fato de seu movimento não ter entrado para os anais da História. E também, de certo modo, na medida em que se afasta, sobretudo, da continuidade da história da literatura brasileira, pensada como uma tradição. Para o poeta e crítico mexicano Octavio Paz, a tradição moderna é sempre uma "tradição da ruptura" (PAZ, 2013), que desaloja qualquer que seja a tradição imperante, em que o que se transmite é a própria intransmissibilidade, em que o que continua não é senão a descontinuidade; é, talvez, neste horizonte que se observa que um dos poucos volumes sobre história da literatura brasileira que tece considerações, ainda que breves, a respeito do poema//processo

Poiésis, Niterói, v. 20, n. 33, jan./jun. 2019. 
é aquele de Gilberto Mendonça Teles, intitulado justamente Vanguarda europeia e modernismo brasileiro (TELES, 1987, pp. 185-186), podendo a ideia de vanguarda funcionar como uma síntese da tradição da ruptura de que fala Octavio Paz.

O próprio Wlademir afirma essa descontinuidade em relação à tradição da poesia moderna brasileira. Em entrevista a Joaquim Branco, datada de 1969, é convidado a responder às seguintes questões: "O poema-processo resolve o problema da atual poesia brasileira? Ou apenas desata o nó concretista?" (BRANCO apud DIAS-PINO, 1971, s/p), ao que o poeta, então, responde:

\section{O nosso movimento nada tem que ver, como continuidade, com a poesia brasil eira (literatura); por isso, recusa, conscientemente, o nome de poesia (estado espiritual) para firmar o de poema (f́́sico) / processo. Ele é uma ruptura, esta é nossa radicalidade". (DIAS-PINO, 1971, s/p)}

E continua, fazendo uma genealogia da moderna poesia brasileira, passando pelo verso branco de Mário de Andrade, a perda da pontuação - que ele atribui, entre outros, de modo no mínimo contestável, a Adalgisa Nery -, a força contra a adjetivação pela valorização do substantivo e do verbo, com Murilo Mendes e Drummond, respectivamente, até João Cabral, com o que ele chama de "estruturação do verso pela gramática" (DIASPINO, 1971, s/p), para chegar no ponto crucial onde o poema//processo interrompe a transmissão dos valores que o poriam na linhagem da tradição:

\section{Assim é que a poesia modernista girou sempre em tôrno da palavra, até mesmo usando-a em estado de dicionário, e nós acentuamos, agora, que o que nos interessa é o projeto do poema. A palavra passa a ser dispensada; nem existe diferença entre a pintura e o poema. A poesia modernista era um problema de língua e o do nosso poema é de linguagem. (DIAS-PINO,1971, s/p)}

É justamente por tratar de um "problema de linguagem", e não de língua, que o poe$\mathrm{ma} /$ processo tem sido inserido mais nos estudos das artes visuais do que da literatura e também porque a trajetória de Wlademir o apresenta como um pesquisador visual, embora ele tenha preferido o "título" de poeta. Mas, embora valha-se de "lugares geométricos, formas e cores" (DIAS-PINO,1971, s/p), os processos operados por esse movimento 
são da ordem do poema - não apenas porque, como já visto na introdução deste estudo, não é possível "determinar nem a necessidade nem a impossibilidade - em princípio - de que a poesia empregue qualquer forma possível" (PUCHEU, 2010, p. 27), podendo utilizar-se, então, "de novos caminhos, de novas matérias, de novas técnicas, de novas formas, de novas linguagens, de novas mídias" (PUCHEU, 2010, p. 24, grifo nosso), mas sobretudo porque, no poema//processo, há sempre uma proposta de leitura. Moacy Cirne comenta:

\section{Por que o poema/processo não é domínio das artes plásticas, embora esteja realmente / bem próximo? Além da voltagem semântica que caracteriza quase todos os nossos poemas, um problema mais impor- tante se apresenta: as direções de leitura. (CRNE, 1968, s/p)}

Isto quer dizer que, enquanto nas artes visuais "lemos a estrutura (leitura abstrata) que, por mais dinâmica que possa ser, encerra sempre uma rigidez operatória", o poe$\mathrm{ma//processo} \mathrm{oferece} \mathrm{uma} \mathrm{possibilidade} \mathrm{de} \mathrm{leitura} \mathrm{circular:} \mathrm{"para} \mathrm{apreender} \mathrm{o} \mathrm{global,} \mathrm{de-}$ pois de um primeiro contato com a obra, e conforme o poema, são necessárias várias leituras (simultâneas ou não) de suas diversas estruturas". (CIRNE, 1968, s/p) O poema reproduzido a seguir (Fig. 1), de Álvaro de Sá, é um exemplo, entre muitos, deste tipo de leitura. Nele, uma seta indica uma possibilidade de leitura (ECO), e outra seta indica, simultaneamente, uma outra (ODE); há ainda as possibilidades que independem das setas. Segundo Wlademir, o poema "assim consegue uma leitura global (mas não monogramática ou figurativa)" (DIAS-PINO, 1971, s/p), na medida em que há diversas estruturas que, tendo estabelecido um projeto de processo, podem se desdobrar em vários outros processos (Fig. 2). Neste caso, as setas ilustram, de maneira mais explícita, o que em outros poemas do movimento aparece apenas como possibilidade, sem a necessidade da ilustração das setas como indicações de leitura. Este poema, portanto, deixa bastante explícito o projeto de multiplicidade de direções de leitura que está no cerne de todo o programa processualista.

Poiésis, Niterói, v. 20, n. 33, jan./jun. 2019. 


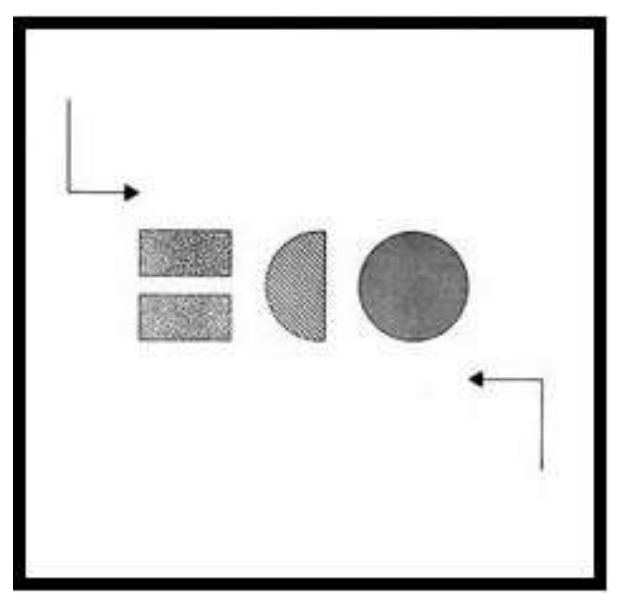

Fig. 1 - Álvaro de Sá, Sem título, 1968.

impressão sobre pape

(Fonte: DIAS-PINO, Wlademir. Processo: linguagem e comunicação. Petrópolis: Editora Vozes, 1971.)

Poiésis, Niterói, v. 20, n. 33, jan./jun. 2019. 


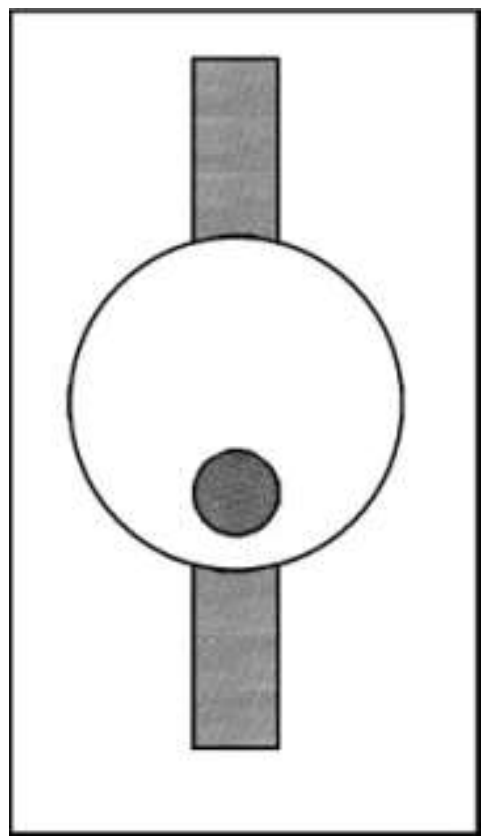

Fig. 2 - Álvaro de Sá, Sem título, 1968.

impressão sobre papel

(Fonte: DIAS-PINO, Wlademir. Processo: linguagem e comunicação. Petrópolis: Editora Vozes, 1971.)

Poiésis, Niterói, v. 20, n. 33, jan./jun. 2019. 
A respeito das diferentes possibilidades de leitura de um poema, Wlademir afirma que, nos poemas figurativos, há uma leitura simbólica - pois o que está em jogo, neste caso, são os símbolos, as imagens (metáforas) que compõem o texto, e que precisam ser decifradas. Ali, há a escrita em seu sentido positivo, como mencionado no início deste artigo: coloca-se uma cifra sob cada pensamento, tornando-o passível de ser decifrado; e não há ausência, corte, cesura implicada neste tipo de escrita. Há ainda, segundo o poeta, uma "leitura abstrata", que é aquela que se dá em relação à estrutura - e teria sido João Cabral o poeta que levou a estrutura a sua potência máxima na poesia brasileira, ao arquitetar, sabidamente, sua forte "engenharia estrutural", que Moacy Cirne chama de "falsa" e diz sempre "terminar na mais pura esterilidade". (CIRNE, 1968, s/p) Mas o processo, diz Wlademir, requer uma "leitura criativa": há que se ler não as imagens do poema, nem sua estrutura, mas as diversas estruturas que encadearam aquele processo, e isso requer do leitor a mesma criatividade que requereu do autor. Essa leitura é circular porque não pode ser feita linearmente: é necessário retomar o processo para visualizar o projeto do poema. "Mais do que a concretização de um objeto o Processo é a visualização do Projeto", diz Wlademir, concluindo: "Estrutura é função; nós queremos é funcionamentos: sistemas". (DIAS-PINO, 1971, s/p)

A "leitura criativa", portanto, de que fala Dias-Pino, é uma leitura sistêmica, que envolve o leitor na engrenagem que faz funcionar o poema enquanto processo/projeto. A estrutura é rígida, e o processo é necessariamente participativo. Assim é que Moacy Cirne afirma:

\section{Sanderson Negreiros amplia a faixa dos poetas: todo consumidor/participante seria também um poeta \\ ("A "operação/poema" tem a vantagem de: ficando o consumidor/participante inteiramente certificado de ter entendido o "projeto", realizará não só os indicados agora, diminutamente, mas fará outros tantos "projetos", que quiser para os realizar em cadeia até reduzi-los a novas concepções e/ou destruições"). (CRNE, 1968, s/p)}

Dias-Pino, manifestando seu descontentamento com a propriedade intelectual e criativa além, evidentemente, da social -, que, em sua concepção, limita o acontecimento do poema enquanto projeto de um processo a partir dos grilhões da autoria, reforça o sentido 
político do poema//processo no seio dessa conjunção de estruturas que geram outras e outras. Assim é que o projeto, no poema//processo, é reutilizável: deve ser apropriado por todos os leitores, que podem (alguns diriam: devem) dar continuidade ao projeto; reprojetá-lo; projetar novos processos; entrar na circularidade desta leitura criativa, desta leitura sistêmica.

Pode-se dizer que essa leitura sistêmica permite uma quebra da hierarquia do olhar do leitor sobre o texto, pensado aqui em sentido ampliado, possibilitando uma leitura circular. No caso do poema//processo, a quebra da hierarquia é, de algum modo, também social, já que a circularidade que ela possibilita é também entre autor e leitor. Em virtude de sua infância passada em uma célula comunista no Mato Grosso, toda a organização de vida do poeta deu-se, em suas palavras, através de uma perspectiva "sectária", querendo com esse termo referir-se, talvez, à ideia de uma perspectiva demasiado segmentada, arregimentada por uma estrutura organizacional rígida. Provém disto, segundo ele, o fato de organizar sua vida quinquenalmente, dedicando cinco anos a cada uma de suas atividades (foi assim que, após cinco anos, o primeiro movimento que ele criou, o Intensivismo, pareceu-Ihe ter durado o suficiente); e provém disto também o fato de ele dedicar cinco anos à leitura e cinco anos à escritura - pois, segundo o poeta, esses dois elementos são interdependentes e concorrem de maneira equivalente para a criação de processos. É deste modo que com a leitura circular, no poema//processo, não se trata apenas de uma quebra da hierarquia do olhar, do ponto de vista formal, embora isso seja extremamente importante: como visto, é essa quebra que elimina a linearidade da leitura figurativa em prol de uma leitura sistêmica, das várias camadas, não de significação, mas de estruturas, de que é composto um poema de processo. Trata-se, neste caso, sobretudo de uma quebra da hierarquia social imposta pelos paradigmas de leitura a que estamos acostumados, pois no poema//processo o leitor participa efetivamente do processo, cabendo a ele, inclusive, apropriar-se de seu projeto para a elaboração de novos.

Observe-se, como exemplo, o poema Baleutros, de Pedro Bertolino (Fig. 3), poeta catarinense que participou do poema//processo:

Poiésis, Niterói, v. 20, n. 33, jan./jun. 2019. 


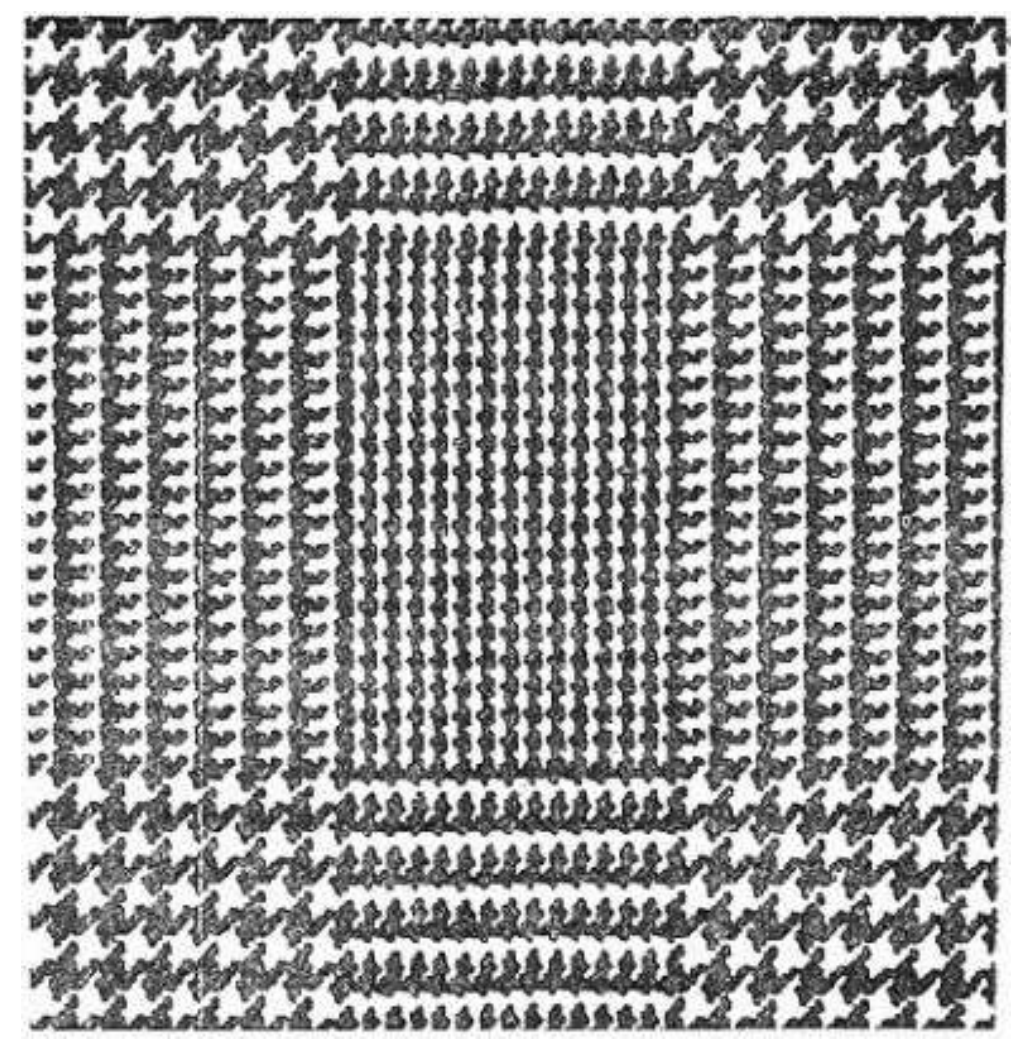

Fig. 3 - Pedro Bertolin, Baleutros, s/d.

impressão sobre papel

(Fonte: DIAS-PINO, Wlademir. Processo: linguagem e comunicação. Petrópolis: Editora Vozes, 1971.) 
Se no exemplo trazido anteriormente (Figs. 1 e 2), o poema de Álvaro de Sá encerrava um processo que partia de uma matriz ainda fortemente alfabética (embora as palavras ECO ou ODE não estivessem escritas de maneira convencional, elas eram perfeitamente legíveis), para apenas no processo seguinte ser desdobrada em uma composição que eliminava mais radicalmente a palavra, sem perder, contudo, a "voltagem semântica", para usar a expressão de Moacy Cirne, neste Baleutros a matriz do processo já elimina radicalmente a palavra, ficando a voltagem semântica a cargo do leitor. E o próprio poeta escreve, a respeito do poema, o seguinte:

\section{Este poema apenas inaugura um processo. 0 consumidor poderá estabelecer sua versão condicionando as formas em preto e / ou branco as noções ou conceitos de sua plena opção. Por exemplo, poderá ler: - "0 EU E 0 OUTRO" - "A ESMOLA E A MISÉRIA" - "NECESSIDADE E SATISFAÇÃO" - "O AMOR E A VIDA" - etc... etc... (BERTOLINO apud DIAS-PINO, 1971, s/p)}

Álvaro de Sá traz a noção de "versão", bastante explorada por Wlademir na consolidação do poema//processo, como índice definitivo dessa participação do consumidor na "leitura" do processo:

Cada consumidor/participante/criativo ao explorar o processo cria ele próprio "versões", de acordo com seu repertório. Se o importante é a invenção de novos processos, todas as "versões" têm igual valor, inclusive a do criador do processo, e os conceitos de bom e ruim são substituídos pela opção de cada um. (SÁ, 1975, p. 55)

Em texto publicado no Jornal do Escritor e reproduzido, sem a data de publicação ou atribuição de autoria (talvez, neste caso, por se tratar de uma visão de todo o movimento do poema//processo), no livro de Dias-Pino, Processo: linguagem e comunicação (1971), é apresentado de maneira mais sistemática como o movimento encara essa noção de versão, que pode ser facilmente atribuída aos poemas aqui apresentados, complementando a ideia de Wlademir de que "a diferença entre um poema processo e o visual, é que o poema processo sempre tem, como prova dos nove, uma versão, enquanto que o poema visual é fechado e concluso". (DIAS-PINO, 2010, s/p) Diz o texto:

Poiésis, Niterói, v. 20, n. 33, jan./jun. 2019. 
Versão - antes de tudo, no primeiro estááio, é a valorização da matriz e, consequentemente, da série; e talvez seja o único critério para a avaliação do poema/processo, uma vez que ele é totalmente em aberto. Se um poema comporta versões, ele encerra um processo. A versão, em segundo estágio, já é o relativo total, uma vez que o poema se auto-supera, acrescido pela experiência de outros autores, até o ponto de consumir todas as possibilidades do poema inaugurador do processo e se incorporar, pelo consumo das versões, à cultura da massa. Criando nova lógica de consumo em contraposição com a descoberta do massificado. (DIAS-PINO, 1971, s/p)

Há ainda alguns casos em que a dimensão social dessa relação entre o autor e o consumidor, que põe em jogo a dinâmica e a potência das versões do mesmo processo e é o que no Poema//Processo constitui mais fortemente essa leitura circular aqui discutida, aparece de forma mais explícita - pois tanto mais explícita será colocada essa dimensão quanto mais ela solicitar um investimento do corpo, tanto do escritor quanto do leitor/consumidor. Submeter-se ao avesso da escrita, buscando o potencial de ausência que há por sob o texto, implica em um reviramento que se dá, no mais das vezes, através do corpo (nele ou com ele). Neste sentido, experiências como o poema A corda, de Neide Sá, ou o Grande Pão Poema, coletivo, trazem à tona a leitura circular em que escritura e leitura participam em pé de igualdade na constituição do processo que se põe em jogo, e fazem-no de forma mais explícita, porque envolvem a presença do corpo (não se trata de tentar asseverar, em hipótese alguma, que a presença do corpo garanta, por si só, o abalamento da hierarquia entre autor e leitor; apenas observa-se que, em alguns casos, e notadamente nestes dois que serão apresentados, essa presença evidencia o aspecto da leitura circular que interessa tratar aqui).

No primeiro caso, Neide Sá cria em 1967 e recria, até 2010, seu poema estendendo uma corda no espaço para que o público pendure, com prendedores de varal de roupa, uma série de textos retirados de revistas da época com os temas mais repetidos pela imprensa, mas também palavras soltas retiradas dessas manchetes, fotos e até objetos que digam respeito a estes assuntos (Neide menciona sutiãs e caixas de pílulas anticoncepcionais). 


\section{Ao falar desse projeto, Neide afirma que sua preocupação maior era com cada pessoa do público, e que procurou criar uma situação em que cada indivíduo pudesse agir livremente, e não como um ser passivo, perdido na massa anônima. Daí o duplo sentido do nome do projeto, que faz referência ao verbo acordar: um estímulo para superar a passividade e o espírito contemplativo, e vislumbrar todo um universo de possibilidades pessoais de criação. (MARGUTTI, 2014, p. 40)}

É um caso em que a leitura só pode ocorrer se houver uma participação do leitor; se o leitor se propuser, efetivamente, a essa co-escritura do processo que se coloca na proposição da poeta. A matriz de que parte o processo, neste caso, não é mais textual, como no primeiro exemplo (ECO - ODE), mas também não é mais somente visual (como a maIha de padronagens em preto-e-branco de Bertolino): ela é matérica, física, e exige uma disposição igualmente física, corporal do consumidor: o processo, aqui, prescinde dos corpos em ação - a corda de Neide (Fig. 4) exige que o leitor acorde, ponha-se em processo junto com o processo do poema.

O outro caso, o Grande pão poema, foi uma espécie de poema-processo-performance que juntou, em abril de 1970, mais de 30 artistas de Pernambuco na Feira de Arte de Recife, no Pátio de São Pedro. Tratava-se de um pão de mais de dois metros de comprimento, apresentado como um poema//processo, que foi comido por todos os presentes na Feira, totalizando quase $5 \mathrm{mil}$ participantes. Amplamente divulgado pela imprensa da época, com nota de destaque no Jornal do Brasil (matéria datada de 07/04/70 sob a manchete "Pão poema-processo com $2 \mathrm{~m}$ é comido por 5 mil pessoas na Feira de Arte de Recife", fac-similada no volume Processo: linguagem e comunicação [DIAS-PINO, 1971]), o acontecimento foi, para Wlademir, o índice mais notável do caráter vanguardista do poe$\mathrm{ma} /$ processo - pois tratou-se de um acontecimento com forte conotação política, evidenciando o problema da fome no Nordeste e solicitando a deglutição literal do poema por parte dos consumidores. O fazimento do pão enquanto poema (ou do poema enquanto pão), que era o processo que estava em jogo naquele caso, funcionava como matriz do outro processo: a deglutição por parte dos "leitores". Ler este poema significava comê-lo - de modo que a leitura não poderia ser simbólica nem abstrata; só poderia ser criativa, ou

Poiésis, Niterói, v. 20, n. 33, jan./jun. 2019. 


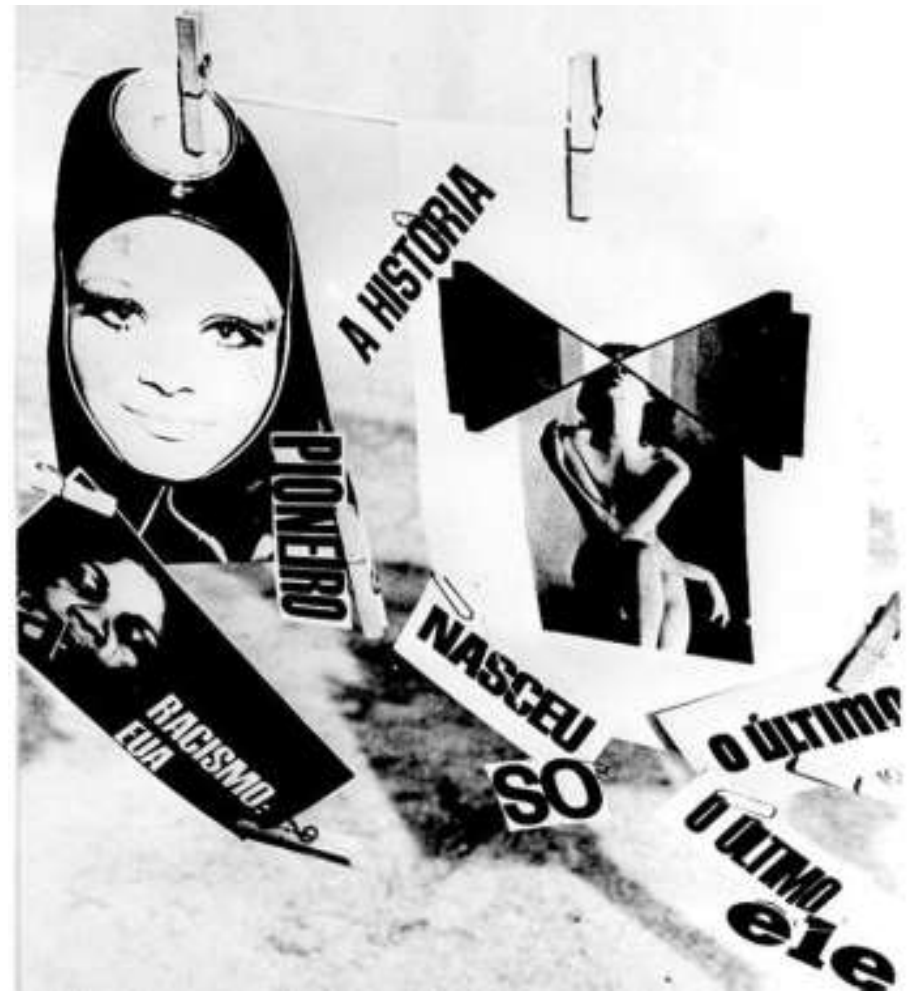

Fig. 4 - Neide Sá, a corda, 1967.

fotografia

(Fonte: MARGUTTI, Mário. Do poema visual ao objeto-poema: a trajetória de Neide Sá. Rio de Janeiro: Editora Lacre, 2014.) 
participativa, ou circular, ou sistêmica (todos os nomes utilizados, aqui, para definir a leitura de que se trata no poema//processo, e que fica mais evidente neste caso); pois só se completa no chamamento ao outro, e mais: à fome (desejo) do outro, ao corpo do outro.

O poema//processo encerra ainda uma série de outras problemáticas que não caberia aqui desenvolver - como sua estreita relação com aparatos da ciência da informação, que levariam uma vertente do movimento a, mais tarde, levá-lo à poesia digital (como o Grupo Poéticas Digitais, da ECA/USP, coordenado por Gilbertto Prado); ou sua aproximação, pela semiótica, a aspectos da publicidade, trabalhados poeticamente, por exemplo, por Philadelpho Menezes, e teoricamente por Lucia Santaella; ou seus desdobramentos em escultura, performance, videoarte e inúmeras outras plataformas que o aproximam ainda mais das artes visuais (é assim que, por exemplo, em Do poema visual ao objeto-poema: a trajetória de Neide Sá, livro recentemente lançado por Mário Margutti sobre a trajetória desta importante participante do movimento do poema//processo e grande amiga e interlocutora de Wlademir Dias-Pino, Neide é apresentada ora como "poeta" ora como "artista" [MARGUTTI, 2014]).

Mas pareceu-nos mais importante acentuar esses elementos do poema//processo que nos fazem deflagrar, nele, aspectos da desescrita ${ }^{5}$ : a ausência de palavra na inauguração de um processo que, sobrepondo várias camadas de estruturas, permite uma leitura circular, onde o consumidor, e em certas experiências o corpo mesmo do consumidor, encontra-se necessariamente implicado, rompendo assim com a hierarquia da escritura sobre a leitura e permitindo que o não-escrito seja parte efetivamente constitutiva do texto, sem que isso opere uma falta.

Poiésis, Niterói, v. 20, n. 33, jan./jun. 2019. 


\section{Notas}

1 Trata-se de uma entrevista que o autor realizou com o poeta, não publicada, em seu estúdio no bairro do Catete, no Rio de Janeiro, em 03/11/2014. Todas as citações indiretas não referenciadas, ao longo do texto, referemse a esta entrevista.

${ }^{2}$ Durante a pesquisa que originou este artigo, várias grafias foram observadas em relação ao nome deste movimento, várias delas grafadas, inclusive, pelo próprio Wlademir, tais como "poema processo", "poema/processo", "poema-processo", e até mesmo "poema de processo". A opção pelo “poema//processo", grafia que será doravante utilizada (salvo por citações em que apareça de modo diferente, em que será preservada a grafia adotada por cada autor), deu-se por ser a que se encontra no último grande estudo acerca da obra de Wlademir: o catálogo de sua exposição retrospectiva no Oi Futuro. (DIAS-PINO, Wlademir. Wlademir Dias-Pino. Rio de Janeiro: Aeroplano, 2010)

${ }^{3}$ Apesar de o Intensivismo, movimento criado por Wlademir Dias-Pino ainda no Mato Grosso, e seus livros-poemas mais importantes antes do poema//processo, A AVE e SOLIDA, se utilizarem da palavra em sua constituição alfabética, é razoável inferir que eles já eram exemplares da postura radical de Wlademir em relação a essa codificação, e que eles já se apresentavam como obras em que a ausência se mostrava implicada como elemento constitutivo de sua poética.

${ }^{4}$ A matéria encontra-se fac-similada no catálogo de sua exposição do Oi Futuro. (DIAS-PINO, Wlademir. Wlademir Dias-Pino. Rio de Janeiro: Aeroplano, 2010)

${ }^{5}$ A expressão "desescrita" foi desenvolvida pelo autor em sua dissertação de mestrado (FERNANDES, Thiago Grisolia. Desescrita: Signos da ausência. Niterói, 2015. 111 f. Dissertação (Mestrado em Estudos Contemporâneos das Artes) - Instituto de Artes e Comunicação Social, Universidade Federal Fluminense, Niterói, 2015). 


\section{Referências}

CAMPOS, Haroldo de. Entrevista a Sonia Salzstein. In SALZSTEIN, Sonia (Org.). No vazio do mundo: Mira Schendel. São Paulo: Marca d'Água, 1996.

CAMPOS, Augusto de; CAMPOS, Haroldo de; PIGNATARI, Décio (Org.). Teoria da poesia concreta: textos críticos e manifestos 1950-1960. Cotia, São Paulo: Ateliê Editorial, 2006.

CIRNE, Moacy. Duas ou três coisas sobre o Poema/Processo. Revista Ponto 2, Rio de Janeiro: Ponto, 1968. Disponível em http://www.poemaprocesso.com.br/textos.php?texto =89. Acesso em abril de 2019 .

DIAS-PINO, Wlademir. Wlademir Dias-Pino. Rio de Janeiro: Aeroplano, 2010.

DIAS-PINO, Wlademir. Processo: linguagem e comunicação. Petrópolis: Editora Vozes, 1971.

MARGUTTI, Mário. Do poema visual ao objeto-poema: a trajetória de Neide Sá. Rio de Janeiro: Editora Lacre, 2014.

PAZ, Octavio. Os filhos do barro: do romantismo às vanguardas. Tradução de Ari Roitman e Paulina Wacht. São Paulo: Cosac Naify, 2013.

PUCHEU, Alberto. Apresentação. In CICERO, Antonio. Antonio Cicero / por Alberto Pucheu. Rio de Janeiro: EdUERJ, 2010.

SÁ, Álvaro de. Vanguarda: produto da comunicação. Rio de Janeiro: Vozes, 1975.

TELES, Gilberto Mendonça. Vanguarda Europeia e Modernismo Brasileiro: apresentação dos principais poemas, manifestos, prefácios e conferências vanguardistas, de 1857 até hoje. Rio de Janeiro: Record, 1987. 